\title{
Knowledge, Utilization and Associated Factors of Postpartum Family Planning Among Women Who Had Delivered a Baby in the Past Year in Oromia Regional State, Ethiopia
}

This article was published in the following Dove Press journal:

Open Access Journal of Contraception

\author{
Benyam Seifu (iD) \\ Delelegn Yilma' \\ Workinesh Daba ${ }^{2}$ \\ 'College of Medicine and Health \\ Sciences, Ambo University, Ambo, \\ Oromia Regional State, Ethiopia; ${ }^{2}$ School \\ of Nursing and Midwifery, Addis Ababa \\ University, Addis Ababa, Ethiopia
}

Background: Globally, 95\% of women wants to avoid pregnancy for at least two years after giving birth, but $70 \%$ of them are not using contraception; majority of them were from developing countries. Postpartum family planning (PPFP) enables families to avoid unplanned pregnancies following 12 months after childbirth. Different studies in Ethiopia showed that the majority of postpartum women do not use PPFP. Moreover, the level of PPFP knowledge and utilization in West Shewa, Oromia region of Ethiopia is unclear.

Purpose: This study aimed to assess the knowledge, utilization and associated factors of postpartum family planning (PPFP) Oromia regional state, Ethiopia.

Methods: A community-based cross-sectional study was conducted in Ambo town, West Shewa Zone of Oromia regional state from April 01 to July 30, 2019. A sample of 367 postnatal women participated in the study. An interview administered questionnaire was used to collect the data and the collected data were entered into Epi Info version 7.1 and analyzed with SPSS version 23. Study participants' characteristics were described using frequency and percentage. Bivariate and multivariate logistic regression was carried out to identify the associated factors with the outcome variables.

Results: A total of 354 women were participated in the study making a response rate of 96.4\%. About 249 (70.3\%) of the respondents had good knowledge about PPFP and 144 (40.7\%) had utilized PPFP services. Higher education level [AOR=3.4, 95\% CI: 1.3-6.9], history of family planning utilization $[\mathrm{AOR}=2.8,95 \% \mathrm{CI}$ : 2.1-4.4] and having ANC followup $[\mathrm{AOR}=2.1,95 \% \mathrm{CI}: 1.1-4.0]$ had showed a positive association with knowledge of PPFP. Meanwhile, knowledge of PPFP [AOR=2.1, 95\% CI: 1.6-3.1], a grand multi-para women $[\mathrm{AOR}=1.7,95 \% \mathrm{CI}(1.3-3.6)]$ and received routine $\mathrm{PNC}$ service [AOR=2.5, 95\% CI: 1.3-5.9] were associated with the utilization of PPFP.

Conclusion and Recommendation: Although the majority of the women knew about PPFP, more than half of them did not utilize PPFP. Due emphasis should be given to improve the utilization of PPFP.

Keywords: postpartum family planning, knowledge, utilization and associated factors

\section{Background}

College of Medicine and Health Sciences,

Ambo University, P.O. Box: 19, Ambo,

Ethiopia

Tel +25I 91045 II 84

Email benyamseifu77@gmail.com
Using family planning help women and her partner to limit or space the number of children. ${ }^{1}$ Postpartum family planning (PPFP) enables families to avoid unplanned pregnancies following 12 months after childbirth. ${ }^{2,3}$ It is recommended that, after 
a woman gave birth, she has to stay for at least two years prior to the next pregnancy to ease the risk of maternal, prenatal, and infant outcome. ${ }^{1}$

Women who gave birth want to avoid pregnancy in the next 2 years, according to reports $95 \%$ of women who gave birth want to avoid pregnancy, but $70 \%$ of them are not using PPFP. Pregnancies within 12 months after giving birth will provoke health risks for pregnant women and their newborn babies. ${ }^{2}$ But women who have recently given birth are amongst those with the highest unmet need for contraception. Maternal mortality increases as the number of children per woman rise to 4 or more. ${ }^{4}$ Unmet need for modern contraceptive methods will have an immediate impact on decreasing unintended pregnancies whose outcome could be postpartum hemorrhage or unsafe abortion, both of which are major causes of maternal mortality. ${ }^{1,2,5}$

The risk of premature birth and low birth weight (less than 2500 grams) increased nearly two times if pregnancy occurs within 6 months after delivery. ${ }^{6}$ Children born from a woman who had delivered a newborn within two years are $60 \%$ more likely to die during infancy than those born greater than two years. ${ }^{7}$ On the contrary, having an interval between pregnancies at least for two years has a significant contribution to averting unplanned pregnancy, abortion, maternal mortality and morbidity, premature birth, infant, and child mortality. ${ }^{8}$ Using PPFP helps women to space pregnancy and this can reduce maternal deaths by $30 \%$ and reduce child mortality by $10 \% .^{1}$ Analysis of 27 countries' demographic and health surveys reported, $65 \%$ of women want to avoid pregnancy in the next twelve months after delivery even though they are not using PPFP. ${ }^{9}$ Moreover, the lowest proportion of women who uses PPFP goes to sub-Saharan Africa, which is $18 \%{ }^{10}$

In Ethiopia based on the 2016 EDHS report, 62\% of women had received at least once ANC from skilled providers, and $32 \%$ of them had the recommended at least four ANC visits during their last pregnancy. The proportion of postnatal care in Ethiopia varied from the lowest $9 \%$ in the Oromia region to the highest $55 \%$ in Addis Ababa. Concerning contraceptives, oral contraceptive pills, injectable, IUDs, implants, and condoms should be available at all private, and government facilities (Hospitals, health centers, health posts, and clinics); while permanent contraceptive methods; Tubal ligation and vasectomy performed surgically are available only in public and private hospitals. GDS. The most common source of contraceptive is the public sector $84 \%$, followed by the private medical sector $14 \%$ and $2 \%$ from other sources including NGOs. ${ }^{11}$

According to the 2011 Ethiopian demographic health survey (EDHS), 9\% of pregnancies occur less than twelve months after prior delivery. ${ }^{12}$ The recent EDHS (2016) showed that the Oromia region has the highest unmet need for family planning in Ethiopia. ${ }^{13}$ Different studies in Ethiopia also showed that the majority of postpartum women do not use PPFP. ${ }^{14-16}$ In areas like the Somalia region, the utilization of PPFP was as low as $12.3 \%{ }^{17}$

A study conducted in Ethiopia, Malawi, and Nigeria reported sub-national variations in the state, regional, and district levels across all three countries. These variations highlight the importance of disaggregated data for evidence-based policymaking and program design. ${ }^{18}$ Similarly, a systematic review in Ethiopia showed variations in prevalence and determinants of across regions. The pooled prevalence of family planning uses among mothers during the postpartum period in Ethiopia was 48.11\% (95\% CI: 36.96, 59.27); where the highest was observed in Addis Ababa (65.4\%), followed by $60.9 \%$ in SNNPR, 48.4\% in Tigray, 39.4\% in Amhara region, and lowest utilization were observed in other regions including Oromia $(28.8 \%){ }^{19}$ The potential rationalization for this variation might be associated with cultural, religious, social, and economical differences across the regions. Hence, investigation of context-specific magnitude and determinants of PPFP utilization will help to design and implement evidence-based context-specific interventions. Moreover, the level of PPFP knowledge and utilization in West Shewa, Ethiopia is unclear. Hence, this study aims to fill the research gap by assessing the knowledge, utilization, and associated factors of PPFP among postpartum women.

\section{Methods}

\section{Study Design and Area}

A community-based cross-sectional study was conducted in Ambo town; the capital of West Shewa Zone Oromia regional state from April 01 to July 30, 2019. The town is located 115 kilometers away from Addis Ababa, the capital city of Ethiopia. The town has 3 urban and 3 rural villages. According to the 2018 Ambo Health Bureau report, the estimated total population of the town was 80,712 , [50.03\% $(39,553)$ of them were males and the remaining $49.97 \%(39,506)$ were females]. 


\section{Sample Size Determination and Sampling Procedure}

The sample size was calculated by using Epi Info version 7.1 software using the following parameters; $p=$ prevalence of knowledge of postpartum family planning $(31.7 \%) .{ }^{20} \mathrm{~d}=$ margin of error is $5 \%, 95 \% \mathrm{CI}=\mathrm{Za} / 2=1.96 \%$ and $10 \%$ nonresponse rate and the final sample size was 367 . The sample size was proportionally allocated for the six villages based on the annual delivery number. The sampling frame for the list of women who delivered in the past one year was obtained from the respective village health Bureau and the participants were selected using simple random sampling using computer-generated random numbers which was computed by Microsoft Excel.

\section{Data Collection}

Data were collected using an interview administered questionnaire. It was pre-tested among $10 \%$ of the sample size of the study participants, which were not included in the actual study. The data were collected from house to house visits by 6 nurses and supervised by two public health professionals. The level of knowledge of PPFP was determined if a woman mentions at least one modern PPFP method, its importance and effectiveness correctly, then she was considered as a woman having good knowledge of PPFP. ${ }^{21}$ If a woman used any modern family planning method within six months after delivery, and this use continued at the time of the interview, then she was considered as utilized PPFP. Regarding the Utilization of ANC and PNC, if the women had at least one visit to health institutions during pregnancy and during the postnatal period, we considered as she utilized ANC and PNC services, respectively.

\section{Data Analysis}

The collected data were entered into Epi-info version 7.1 and exported to SPSS version 23 for data processing and analysis. Descriptive characteristics were presented in frequency with percent and mean with standard deviation. Logistic regression analysis was carried out to identify the associated factors of knowledge and utilization of PPFP. All explanatory variables that were significantly associated with the outcomes variable in the bivariate analyses were entered into the multivariate logistic regression model. Crude and adjusted odds ratios with their $95 \%$ confidence interval (CI) were determined and statistically significant association was asserted based on $P$-value less than 0.05 . Multi-collinearity was checked using the variance inflation factor.
This study was conducted by obtaining ethical clearance from Ambo university ethical review board and Ambo town health office. The study was also conducted in accordance with the Declaration of Helsinki.

\section{Results}

\section{Socio-Demographic Characteristics}

A total of 354 study participants were involved in the study making a response rate of $96.4 \%$. The mean age of the study participants was 29.8 with a standard deviation (SD) of \pm 3 years with the age range of 17 to 44 years. The majority of the study participants were Oromo in ethnicity $323(91.2 \%)$ and $188(53.1 \%)$ were protestant by religion. Three hundred five $(86.2 \%)$ attended formal education and nearly half of the study participants were housewives 162 (45.8\%). Regarding the place of residence, $206(58.2 \%)$ was an urban resident (Table 1).

Table I Socio-Demographic Characteristics of Women Who Had Delivered a Baby in the Past One Year in West Shewa, Oromia Region, Ethiopia $(n=354)$

\begin{tabular}{|c|c|c|c|}
\hline Variable & Category & Frequency & Percent \\
\hline Age & $\begin{array}{l}\leq 20 \\
21-30 \text { years old } \\
31-40 \text { years old } \\
>40 \text { years }\end{array}$ & $\begin{array}{l}22 \\
186 \\
118 \\
28\end{array}$ & $\begin{array}{l}6.2 \\
52.5 \\
33.3 \\
7.9\end{array}$ \\
\hline Ethnic group & $\begin{array}{l}\text { Oromo } \\
\text { Amhara } \\
\text { Tigre } \\
\text { Gurage }\end{array}$ & $\begin{array}{l}323 \\
14 \\
7 \\
10\end{array}$ & $\begin{array}{l}91.2 \\
4.0 \\
2.0 \\
2.8\end{array}$ \\
\hline Religion & $\begin{array}{l}\text { Orthodox } \\
\text { Protestant } \\
\text { Muslim }\end{array}$ & $\begin{array}{l}135 \\
188 \\
31\end{array}$ & $\begin{array}{l}38.1 \\
53.1 \\
8.8\end{array}$ \\
\hline $\begin{array}{l}\text { Educational } \\
\text { status }\end{array}$ & $\begin{array}{l}\text { No formal education } \\
\text { Primary } \\
\text { Secondary } \\
\text { High school } \\
\text { College/university }\end{array}$ & $\begin{array}{l}49 \\
88 \\
44 \\
69 \\
104\end{array}$ & $\begin{array}{l}13.8 \\
24.9 \\
12.4 \\
19.5 \\
29.4\end{array}$ \\
\hline Occupation & $\begin{array}{l}\text { Government } \\
\text { employee } \\
\text { House wife } \\
\text { Merchant } \\
\text { Student } \\
\text { Privet employee }\end{array}$ & $\begin{array}{l}108 \\
162 \\
47 \\
21 \\
16\end{array}$ & $\begin{array}{l}30.5 \\
45.8 \\
13.3 \\
5.9 \\
4.5\end{array}$ \\
\hline $\begin{array}{l}\text { Place of } \\
\text { residence }\end{array}$ & $\begin{array}{l}\text { Urban } \\
\text { Rural }\end{array}$ & $\begin{array}{l}206 \\
148\end{array}$ & $\begin{array}{l}58.2 \\
41.8\end{array}$ \\
\hline
\end{tabular}




\section{Obstetric and Maternal Service Utilization History}

Concerning obstetric history, 154 (43.5\%) of the study participants had four or more children and 270 (76.3\%) had a history of FP utilization. The implant was the most frequently used family planning (FP) method 104 (38.5\%). Regarding maternal health services, 274 (77.4\%) had ANC follow-up, $221(62.4 \%)$ of them delivered their baby in a health institution and $186(52.5 \%)$ received postnatal care (Supplementary Table 1).

\section{Knowledge and Utilization of PPFP}

All of the respondents ever heard about PPFP at least once. About 249 (70.3\%) of the respondents had good knowledge of PPFP. Regarding the utilization of PPFP, 144 (40.7\%) used PPFP (Figure 1). The most commonly mentioned modern family planning was Injectable 74 (20.9\%) and implants 69 (19.5\%). The main source of information was health professionals $154(43.5 \%)$ and $141(39.8 \%)$ know that FP enables women to control birth spacing. Most of the study participants 271 (76.6\%) discussed FP with their husbands and 251 (70.9\%) stated that their husbands supported them to use FP. For those women who utilized PPFP, 67 (46.5\%) of them used an implant. Among the women who did not utilize PPFP, the main reason for not utilizing PPFP was to get more child and fear of side effects 52 (24.8\%) and 48 (22.9\%) respectively (Table 2).

\section{Factors Associated with Knowledge and Utilization of PPFP}

The independent factors associated with knowledge of PPFP were educational status, history of FP utilization and ANC follow-up. Women with higher educational status (college and above) were 3.4 times more likely to have a good knowledge of PPFP than those who did not attend formal education $[\mathrm{AOR}=3.4,95 \% \mathrm{CI}: 1.3-6.9]$. Women who had a history of modern FP utilization were nearly three times more likely to know about PPFP than those women who had no history of modern FP utilization [AOR=2.8, 95\% CI: 2.1-4.4]. Women who had ANC follow-up in their recent pregnancy were found to be two times more likely to have a good PPFP knowledge compared with those who do not had ANC follow-up in their last pregnancy [AOR=2.1, 95\% CI: 1.1-4.0] (Table 3).

Regarding factors associated with utilization of PPFP, Age, Knowledge of PPFP, number of children and PNC utilization showed association during bivariate analysis. But age was cofounded during the multiple logistic regression analysis while the other three variables showed a significant association (P-value $<0.05$ ). Study participants who had good knowledge of PPFP were two times more likely to utilize PPFP than those women who had poor knowledge of PPFP [AOR=2.1, 95\% CI: 1.6-3.1]. Grand Multi-Para women (had four and more children) were 1.7 times more likely to utilize PPFP than those who had only one child [AOR=1.7, 95\% CI (1.3-3.6)]. In addition, study participants who utilized routine PNC services were 2.5 times more likely to utilize PPFP than those

Knowledge and Utilization of Postpartum Family Planning

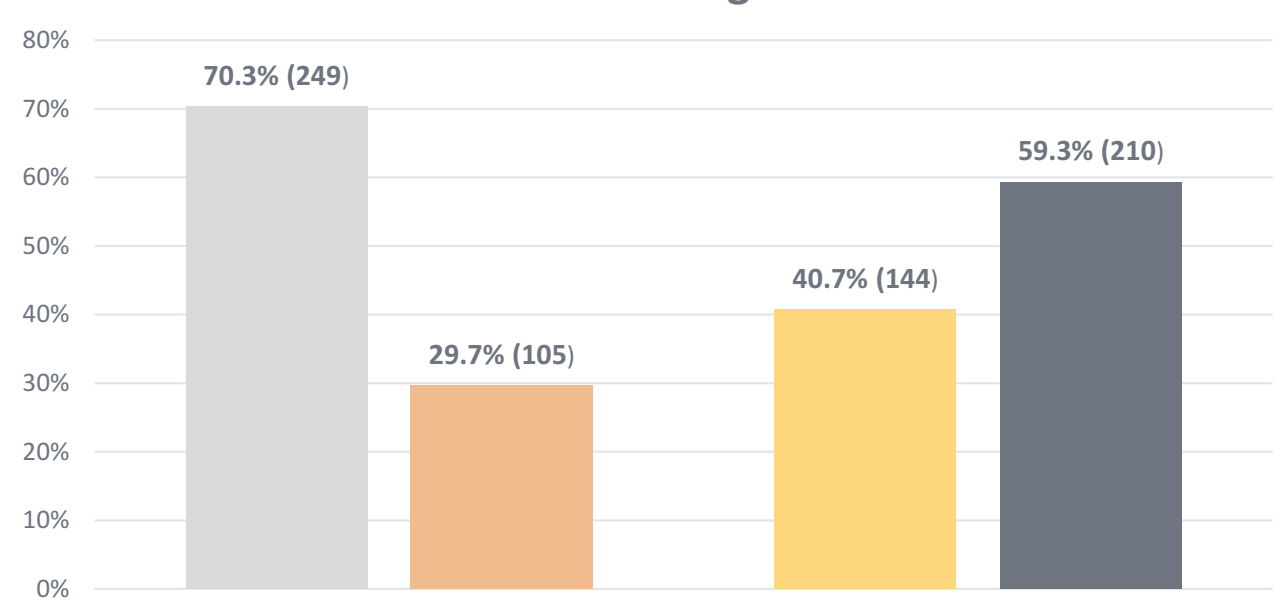

Figure I Knowledge and utilization of PPFP among women who had delivered a baby in the past one year in west Shewa, Oromia region, Ethiopia ( $\mathrm{n}=354$ ). 
Table 2 Knowledge and Utilization of PPFP Among Women Who Had Delivered a Baby in the Past One Year in West Shewa, Oromia Region, Ethiopia $(n=354)$

\begin{tabular}{|c|c|c|c|}
\hline Variable & Category & Frequency & Percent \\
\hline \multirow{5}{*}{$\begin{array}{l}\text { Which method of modern FP you know } \\
\text { (more than one answer was possible) }\end{array}$} & Pills & 48 & 13.6 \\
\hline & Implant & 69 & 19.5 \\
\hline & Injectable & 74 & 20.9 \\
\hline & IUD (intrauterine device) & 12 & 3.4 \\
\hline & More than one FP & 86 & 24.3 \\
\hline \multirow[t]{4}{*}{ Where do you get information } & Mass media & 73 & 20.6 \\
\hline & Health professionals & 154 & 43.5 \\
\hline & Health extension & 87 & 24.6 \\
\hline & Neighbors & 40 & 11.3 \\
\hline \multirow[t]{5}{*}{ Reason women use Modern FP } & Prevention of unwanted pregnancy & 93 & 26.2 \\
\hline & Child spacing & 141 & 39.8 \\
\hline & To limit family size & 85 & 24.0 \\
\hline & Prevention of STI/HIV & 14 & 4.0 \\
\hline & Other* & 21 & 6.0 \\
\hline \multirow{2}{*}{ Discussed about FP with your husband } & Yes & 271 & 76.6 \\
\hline & No & 83 & 23.4 \\
\hline \multirow[t]{2}{*}{ Your husband supported you to use FP } & Yes & 251 & 70.9 \\
\hline & No & 103 & 29.1 \\
\hline \multirow[t]{4}{*}{ Current PPFM used } & Pills & 25 & 17.5 \\
\hline & Implant & 67 & 46.5 \\
\hline & Injectable & 44 & 30.5 \\
\hline & IUDs & 8 & 5.5 \\
\hline \multirow[t]{6}{*}{ Reason for not utilizing PPFP } & To get more child & 52 & 24.8 \\
\hline & Family disapproval & 38 & 18.1 \\
\hline & Religious reason & 28 & 13.3 \\
\hline & Fear of side effect & 48 & 22.9 \\
\hline & Inaccessibility & 32 & 15.2 \\
\hline & Others** & 12 & 2.7 \\
\hline \multirow[t]{2}{*}{ Is PPFP culturally acceptable in your context } & Yes & 237 & 66.9 \\
\hline & No & 117 & 33.1 \\
\hline
\end{tabular}

Notes: *Ordered by physician or nurses, for medical treatment, to prevent abnormal menstruation. **Personal belief, not knowing the importance, fear of harm on the breastfeeding baby.

who did not utilized PNC in their last pregnancy [AOR=2.5, 95\% CI:1.3-5.9] (Table 4).

\section{Discussion}

This study provides key findings regarding PPFP. About three-fourth of the study participants had good knowledge of PPFP, which was found to be lower than other comparable studies from central Ethiopia, Thailand, and Nepal. ${ }^{3,16,22}$ Nonetheless it was higher than the study from Axum, Ethiopia (46\%). ${ }^{23}$ The variance may be due to the differences in the study period and socio-demographic characteristics. This study also found out $41 \%$ of the study participants utilize PPFP. This figure was similar to most of the studies conducted in Sub-Sharan African countries. The prevalence of PPFP utilization in these studies ranged from $40 \%$ to $49 \%{ }^{14,16,23,24}$ But the lower figure was reported in Somalia Region, Ethiopia (12.3\%). ${ }^{17}$ This disparity might be due to socio-demographic and the difference in $\mathrm{MCH}$ service coverage of the two regions. ${ }^{13}$

A study conducted to assess the patterns and trends of postpartum family planning in Ethiopia, Malawi, and Nigeria, also found sub-national variations at the state, regional, and district levels across all three countries. The observed variations point more to variance in 
Table 3 Factors Associated with Knowledge of PPFP of Women Who Had Delivered a Baby in the Past One Year in West Shewa, Oromia Region, Ethiopia $(n=354)$

\begin{tabular}{|c|c|c|c|c|}
\hline \multirow[t]{3}{*}{ Variables } & \multicolumn{2}{|c|}{ Knowledge of PPFP } & \multirow[t]{3}{*}{ COR $(95 \% \mathrm{Cl})$} & \multirow[t]{3}{*}{ AOR $(95 \% \mathrm{Cl})$} \\
\hline & \multicolumn{2}{|c|}{ Frequency (\%) } & & \\
\hline & Good & Poor & & \\
\hline \multicolumn{5}{|l|}{ Educational status } \\
\hline No formal education & $28(57.1)$ & $21(42.9)$ & I & I \\
\hline Primary & $60(68.2)$ & $28(31.8)$ & $1.8(0.7-3.6)$ & $1.5(0.6-3.4)$ \\
\hline Secondary & $28(63.6)$ & $16(36.4)$ & $1.3(0.6-3.5)$ & $1.2(0.5-3.1)$ \\
\hline High school & $50(72.5)$ & $19(27.5)$ & $2.3(1.1-6.7)^{* *}$ & $0.9(0.9-5.6)$ \\
\hline College/university & $83(79.8)$ & $21(20.2)$ & $3.0(1.5-8.2)^{*}$ & $3.4(1.3-6.9)^{* *}$ \\
\hline \multicolumn{5}{|l|}{ History of FP utilization } \\
\hline Yes & $213(78.9)$ & $57(21.1)$ & $4.9(2.3-6.7)^{* *}$ & $2.8(2.1-4.4)^{* *}$ \\
\hline No & $36(65.5)$ & $48(34.5)$ & $\mathrm{I}$ & 1 \\
\hline \multicolumn{5}{|l|}{ ANC follow-up } \\
\hline Yes & $205(74.8)$ & $69(25.2)$ & $2.4(1.4-4.6)^{* *}$ & $2.1(1.1-4.0)^{* *}$ \\
\hline No & $44(55)$ & $36(45)$ & 1 & 1 \\
\hline
\end{tabular}

Notes: *P-value less than 0.05 , **P-value less than 0.001 .

Table 4 Factors Associated with Utilization of PPFP of Women Who Had Delivered a Baby in the Past One Year in West Shewa, Oromia Region, Ethiopia $(n=354)$

\begin{tabular}{|c|c|c|c|c|}
\hline \multirow[t]{3}{*}{ Variables } & \multicolumn{2}{|c|}{ PPFP Utilization } & \multirow[t]{3}{*}{ COR $(95 \% \mathrm{Cl})$} & \multirow[t]{3}{*}{ AOR $(95 \% \mathrm{Cl})$} \\
\hline & \multicolumn{2}{|c|}{ Frequency (\%) } & & \\
\hline & Yes & No & & \\
\hline \multicolumn{5}{|l|}{ Age group } \\
\hline$\leq 20$ & $8(36.4)$ & $14(63.6)$ & 1 & I \\
\hline $21-30$ & $68(36.5)$ & $118(63.5)$ & I.I (0.8-4.2) & $1.3(0.7-3.8)$ \\
\hline $31-40$ & $57(48.3)$ & $61(51.7)$ & $1.6(1.2-5.7)^{*}$ & $2.1(0.6-6.6)$ \\
\hline$>40$ & II (39.3) & $17(60.7)$ & $1.2(0.8-9.6)$ & I.I (0.9-7.4) \\
\hline \multicolumn{5}{|l|}{ Knowledge of PPFP } \\
\hline Good & $|2|(48.6)$ & $128(5 \mid .4)$ & $3.4(2.8-4.7)^{* *}$ & $2.1(1.6-3.1)^{*}$ \\
\hline Poor & $23(30.3)$ & $82(78.1)$ & I & I \\
\hline \multicolumn{5}{|c|}{ Number of alive children } \\
\hline One & $23(32.4)$ & $48(67.6)$ & 1 & 1 \\
\hline Two or three & $49(38)$ & $80(62)$ & $1.3(0.6-2.3)$ & $1.6(0.8-3.1)$ \\
\hline Four and more & $72(46.8)$ & $82(53.2)$ & $1.9(1.4-4.5)^{*}$ & $1.7(1.3-3.6)^{*}$ \\
\hline \multicolumn{5}{|l|}{ PNC Utilization } \\
\hline Yes & $98(52.7)$ & $88(47.3)$ & $2.9(1.4-4.6)^{* *}$ & $2.5(1.3-5.9)^{* *}$ \\
\hline No & $46(27.4)$ & $122(72.6)$ & 1 & I \\
\hline
\end{tabular}

Notes: *P-value less than 0.05 , ${ }^{*}$ P-value less than 0.001 .

opportunities in access and supply of the service or social and cultural behavioral norms. ${ }^{18}$ The socio-economic difference in education, residence, and wealth quintile of the women also played a significant role in the variations of modern contraception utilization in the postpartum period.
Access to information and services is generally better in urban areas and for the wealthiest women. ${ }^{18,25}$ The high unmet need of FP in Ethiopia is due to inaccessibility of quality service, women insufficient information regarding side effects, and the availability of methods. ${ }^{26}$ Cultural 
influence like husbands or religious prohibition of contraceptives. $^{27}$ These differences suggest that contextspecific interventions are required in order to improve contraceptive use during the postpartum period. Community-based interventions may need to be prioritized in regions where maternal and child care utilization rates are low. While in regions where institutional delivery rates are high integrating family planning services in the maternal and child routine care may be a successful approach. $^{25}$

Women with higher education were more likely to know about PPFP. This finding was comparable with different works of literature which concluded that women with a better educational background have a better knowledge about PPFP. ${ }^{3,21,22,28}$ Moreover, women who had the experience of using modern FP were found to be knowledgeable about modern FP. $^{29}$ This could be due to the counseling and health education provided during contraceptive methods provision. ${ }^{5,23}$ Similarly, having an ANC follow-up was also significantly associated with knowledge of PPFP. ${ }^{14,29}$ A study was done in Nepal also showed that the main source of information was health professionals during ANC. ${ }^{4}$ This finding was also supported by a study from Axum, Northern Ethiopia. ${ }^{29}$

In this study, ANC was not significantly associated with postpartum contraceptive use. Similarly, when exploring the association of opportunistic contacts with the health system, we did not see a consistent relationship between ANC visits (irrespective of the number of visits) and the use of modern contraception in the postpartum period across countries. The result may reflect the absence of provision of family planning information and services during ANC. It may also indicate that a woman does not act on information unless it is given to her at a moment when she can act upon it effectively. In addition, proper ANC visits, when well conducted, could be associated with effective postnatal care. The lack of capacity and integration of maternal health services with family planning services results in missed opportunities. ${ }^{18}$ However, a recent systemic review in Ethiopia indicated resumed sexual activity, antenatal care, secondary and above level of maternal education, postnatal care, menses resumption, and postpartum period $\geq 6$ months were found to be significantly associated with postpartum contraceptive use. ${ }^{19}$

Knowledge about PPFP was significantly associated with its utilization. This was also supported by the finding of a study conducted in Nepal, ${ }^{22}$ and Ethiopia. ${ }^{14,17,23,24}$ A systematic review conducted in Ethiopia also showed that women with an inadequate level of knowledge was associated with a low level of utilizing FP. ${ }^{30}$ An increase in the number of living children was directly associated with PPFP utilization. It was consistent with the study conducted in Burundi and Rwanda, which revealed that "the odds of utilizing PPFP increased by nearly $30 \%$ with an additional living child for a woman". The most commonly mentioned reasons for PPFP utilization were to prevent unwanted pregnancy, limit family size, and child spacing. ${ }^{31}$

This study also indicated that PNC service utilization was significantly associated with the utilization of PPFP. This was consistent with the finding of previously conducted studies in Ethiopia. For instance, a study conducted in southern Ethiopia showed that women who utilized PNC service were nearly two times more likely to utilize PPFP. ${ }^{14}$ In addition, this finding was also evidenced in the studies conducted in Gonder ${ }^{23}$ and the Tigray region, Ethiopia. ${ }^{15}$ This could be attributed to the inclusion of counseling and the promotion of contraceptive service during the routine PNC services. ${ }^{1,2,14}$ This may indicate that women who use maternal and newborn health services (PNC, institutional delivery, child immunization) are also more likely to use postpartum family planning services, or that by attending these services they have more opportunities to be convinced to use them and are provided with a method. While the lack of capacity and integration of family planning services with maternal health services results in missed opportunities that could increase the use of PPFP. ${ }^{18}$

The reasons for not utilizing PPFP were; want to have more children, fear of the side effect of modern FP, family disapproval, inaccessibility, and cultural and religious factors. A study conducted in Tigray, Ethiopia showed that women who experience side effects had lower utilization of FP than their counterparts ${ }^{14}$ and fear of the possible side effect also found to be negatively associated with utilization of FP in developing countries. ${ }^{22}$ Likewise, a study from Nepal showed that women with few numbers of children have low intention to use modern $\mathrm{FP}^{22}$ According to the study conducted in Sudan, religious beliefs and lack of support from husband were found to be a significant factor for non-utilizing FP. ${ }^{32}$ Support from husband was also found to be significantly associated with the utilization of PPFP among studies conducted in Ethiopia. $^{24,29}$ Accessibility of Modern family planning also one of the factors that determine the utilization PPFP in the study conducted in Northern Ethiopia. ${ }^{14}$ 
Religious and cultural factors also influence the acceptance and utilization of contraception during the postpartum period. ${ }^{18}$ In this study, about one-third of women said that PPFP is not culturally acceptable, which is one of the main challenges to improve the PPFP utilization rate in Ethiopia. Studies also reported cultural norms that encourage childbearing and religious prohibition of contraceptives for postpartum mothers. ${ }^{25}$ This indicates that tailoring discussions during antenatal care, educating the community about the benefits of birth spacing using community-based strategies are required in order to overcome cultural related obstacles for PPFP use. In Ethiopia, health extension workers have responsibility for community-level reproductive health services, including counseling and provision of some contraceptive methods and referrals for others. The evidence also showed male involvement associated with improved maternal health service utilization, including FP in developing countries. ${ }^{33}$ In addition, educating community leaders and religious institution leaders, and mass media education can play an important role in improving community awareness of contraceptive related issues, myths and misconceptions about contraceptives, unwanted pregnancy, abortion and disseminating information on the availability of services. ${ }^{34}$

Finally, we would like to inform our readers that this study was conducted using the sampling frame of women delivered within one year prior to the data collection which was obtained from the Ambo town health office. However, there may be women who are not yet registered to the vital statistics that may be a source of selection bias. And also, since this is a cross-sectional study, it does not show the temporal cause and effect relationship between dependent variables and the associated factors. Finally, the measurements of knowledge and utilization postpartum tools are operationally defined according to our setting and from other similar findings, and these tools are not validated. Therefore, we recommend our readers to consider these limitations while reading, interpreting the findings, and also while considering to cite this study.

\section{Conclusions and Recommendations}

Most of the study participants had favorable knowledge about PPFP. However, more than half of postpartum women did not utilize PPFP. Educational status, history of FP utilization and ANC follow-up were positively associated with knowledge of PPFP. While knowledge of PPFP, the number of children and PNC service were the independent predictors of PPFP utilization. Therefore, strengthening $\mathrm{MCH}$ services like ANC and PNC service utilization will improve woman's knowledge and utilization of PPFP. In order to tackle barriers of PPFP utilization, health-care providers and policy-makers should develop continuous community-based counseling and interventions which ensures active participation of husbands, religious leaders and elderlies.

\section{Abbreviations}

ANC, antenatal care; AOR, adjusted odds ratio; $\mathrm{COR}$, crude odds ratio; CI, confidence interval; EDHS, Ethiopian demographic health survey; FP, family planning; HIV, human immune viruses; IUD, intrauterine device; PNC, postpartum care; PPFP, postpartum family planning; STI, sexually transmitted infections; WHO, World Health Organization.

\section{Data Sharing Statement}

Full data for this research is available through the corresponding author up on request.

\section{Consent for Publication}

Not applicable.

\section{Ethics Approval and Consent for Publication}

Ethical clearance was obtained from the institutional review board (IRB) of Ambo University. Following the approval by the IRB, an approval letter was obtained from the Ambo town health bureau. The purpose of the study was explained to all study participants and written consent was taken; they were also informed that all of their responses are confidential and anonymous, and they have all the right not to be involved in the study or not to answer any of the questions.

\section{Acknowledgments}

We would like to express deepest and heartfelt thanks to Ambo University for funding this study. We also like to thank Ambo town administration, health office. Finally, we send our gratitude for all individuals and institutions help us, including data collectors, supervisors and study participants.

\section{Author Contributions}

All authors (BS, DY and WD) made a significant contribution to the conception, study design, execution, acquisition of data, analysis and interpretation; gave final approval of the version to be published; have agreed on the journal to which the article has been submitted; and agree to be accountable for all aspects of the work. 


\section{Funding}

Ambo University.

\section{Disclosure}

The authors declare that they have no competing interests.

\section{References}

1. WHO. Programming strategies for postpartum family planning; 2013. Available from: www.who.int.

2. Christina F, Julia G, Jiantong W, Beth L, Wilson E. Family Planning Annual Report: 2018 National Summary. Research Triangle Park, NC: RTI International; 2018.

3. Salisbury P, Hall L, Kulkus S, et al. Family planning knowledge, attitudes and practices in refugee and migrant pregnant and post-partum women on the Thailand-Myanmar border - a mixed methods study. Reprod Health. 2016;13(1):94.

4. Bhusal CK, Bhattarai S. Factors affecting unmet need of family planning among married Tharu women of Dang District, Nepal. Int J Reprod Med. 2018;2018:9312687. doi:10.1155/2018/9312687

5. MOH F. National Guideline for Family Planning Services in Ethiopia. Federal Democratic Republic of Ethiopia, Ministry of Health; 2011.

6. Blencowe H, Cousens S, Oestergaard MZ, et al. National, regional, and worldwide estimates of preterm birth rates in the year 2010 with time trends since 1990 for selected countries: a systematic analysis and implications. Lancet (London, England). 2012;379 (9832):2162-2172. doi:10.1016/S0140-6736(12)60820-4

7. Moucheraud C, Worku A, Molla M, Finlay JE, Leaning J, Yamin A. Consequences of maternal mortality on infant and child survival: a 25-year longitudinal analysis in Butajira Ethiopia (1987-2011). Reprod Health. 2015;12(Suppl1):S4-S4.

8. Tsui AO, McDonald-Mosley R, Burke AE. Family planning and the burden of unintended pregnancies. Epidemiol Rev. 2010;32:152-174.

9. Pasha O, Goudar SS, Patel A, et al. Postpartum contraceptive use and unmet need for family planning in five low-income countries. Reprod Health. 2015;12(S2):S11. doi:10.1186/1742-4755-12-S2-S11

10. Tsui AO, Brown W, Li Q. Contraceptive practice in Sub-Saharan Africa. Popul Dev Rev. 2017;43(Suppl Suppl 1):166-191. doi:10.1111/padr.12051

11. (CSA) CSA, ICF. Ethiopia Demographic and Health Survey. Addis Ababa, Ethiopia, and Rockville, Maryland, USA: CSA and ICF; 2016

12. ECSA, International I. 2011 Ethiopia Demographic and Health Survey: Key Findings. Calverton, Maryland, USA: CSA and ICF International; 2012.

13. CSACE and ICF. Ethiopia Demographic and Health Survey 2016. Addis Ababa, Ethiopia, and Rockville, Maryland, USA: CSA and ICF; 2016.

14. Abraha TH, Teferra AS, Gelagay AA. Postpartum modern contraceptive use in northern Ethiopia: prevalence and associated factors. Epidemiol Health. 2017;39:e2017012. doi:10.4178/epih.e2017012

15. Abraha TH, Gebrezgiabher BB, Aregawi BG, Belay DS, Tikue LT, Welay GM. Predictors of postpartum contraceptive use in rural Tigray region, northern Ethiopia: a multilevel analysis. BMC Public Health. 2018;18(1):1017. doi:10.1186/s12889-018-5941-4

16. Gezahegn T, Kolola T. postpartum-family-planning-utilizationamong-postpartum-women-inpublic-health-institutions-of-debreberhan-town-ethiopia-2167-0420-1000426. J Women's Health Care. 2018;7.

17. Nigussie AT, Girma D, Tura G. Postpartum family planning utilization and associated factors among women who gave birth in the past 12 months, Kebribeyah Town, Somali Region, Eastern Ethiopia. $J$ Women's Health Care. 2016;05.
18. Hounton S, Winfrey W, Barros AJD, Askew I. Patterns and trends of postpartum family planning in Ethiopia, Malawi, and Nigeria: evidence of missed opportunities for integration. Glob Health Action. 2015;8(1):29738. doi:10.3402/gha.v8.29738

19. Tsegaye M, Birhanie M, Zelalem Belayneh A, Sharew Y. Postpartum contraceptive use and its determinants in Ethiopia: a systematic review and meta-analysis. Hindawi Int J Reprod Med. 2020.

20. Dona A, Abera M, Alemu T, Hawaria D. Timely initiation of postpartum contraceptive utilization and associated factors among women of child bearing age in Aroressa District, Southern Ethiopia: a community based cross-sectional study. BMC Public Health. 2018;18(1):1100. doi:10.1186/s12889-018-5981-9

21. Ahmed FA, Moussa KM, Petterson KO, Asamoah BO. Assessing knowledge, attitude, and practice of emergency contraception: a crosssectional study among Ethiopian undergraduate female students. $B M C$ Public Health. 2012;12(1):110. doi:10.1186/1471-2458-12-110

22. Bajracharya A. Knowledge, attitude and practice of contraception among postpartum women attending Kathmandu medical college teaching hospital. Kathmandu Univ Med J. 2015;13(4):292-297. doi:10.3126/kumj.v13i4.16826

23. Abera Y, Mengesha ZB, Tessema GA. Postpartum contraceptive use in Gondar town, Northwest Ethiopia: a community based cross-sectional study. BMC Women's Health. 2015;15(1):19. doi:10.1186/s12905-015-0178-1

24. Berta M, Feleke A, Abate T, Worku T, Gebrecherkos T. Utilization and associated factors of modern contraceptives during extended postpartum period among women who gave birth in the last 12 months in Gondar Town, Northwest Ethiopia. Ethiop J Health Sci. 2018;28(2):207-216. doi:10.4314/ejhs.v28i2.12

25. Dev R, Kohler P, Feder M, Unger JA, Woods NF, Drake AL. A systematic review and meta-analysis of postpartum contraceptive use among women in low- and middle-income countries. Reprod Health. 2019;16(1):154. doi:10.1186/s12978-019-0824-4

26. Hrusa G, Spigt M, Dejene T, Shiferaw S, Zhang S. Quality of family planning counseling in Ethiopia: trends and determinants of information received by female modern contraceptive users, evidence from national survey data, (2014-2018). PLoS One. 2020;15(2):e0228714. doi:10.1371/journal.pone.0228714

27. Getaneh T, Negesse A, Moltot T. Prevalence Unmet Need for Family Planning and Its Associated Factors in Ethiopia 2019: Systematic Review and Meta Analysis. Research Square; 2019.

28. Sedgh G, Hussain R. Reasons for contraceptive nonuse among women having unmet need for contraception in developing countries. Stud Fam Plann. 2014;45(2):151-169.

29. Abraha TH, Belay HS, Welay GM. Intentions on contraception use and its associated factors among postpartum women in Aksum town, Tigray region, northern Ethiopia: a community-based cross- sectional study. Reprod Health. 2018;15(1):188. doi:10.1186/s12978-018-0632-2

30. Dasa TT, Kassie TW, Roba AA, Wakwoya EB, Kelel HU. Factors associated with long-acting family planning service utilization in Ethiopia: a systematic review and meta-analysis. Contracept Reprod Health Care. 2019;4(1):14. doi:10.1186/s40834-019-0095-z

31. Rutaremwa G, Kabagenyi A. Postpartum family planning utilization in Burundi and Rwanda: a comparative analysis of population based cross-sectional data. Pan Afr Med J. 2018;30:303. doi:10.11604/ pamj.2018.30.303.15105

32. Handady S, Naseralla K, Sakin H, Alawad A. Knowledge, attitude and practice of family planning among married women attending primary health center in Sudan. Int J Public Health. 2015;3:243-247.

33. Yargawa J, Leonardi-Bee J. Male involvement and maternal health outcomes: systematic review and meta-analysis. $J$ Epidemiol Community Health. 2015;69(6):604-612.

34. Samuel M, Fetters T, Desta D. Strengthening postabortion family planning services in Ethiopia: expanding contraceptive choice and improving access to long-acting reversible contraception. Glob Health Sci Pract. 2016;4:S60-S72. 


\section{Publish your work in this journal}

Open Access Journal of Contraception is an international, peerreviewed, open access, online journal, publishing original research, reports, reviews and commentaries on all areas of contraception. In addition to clinical research, demographics and health-related aspects, the journal welcomes new findings in animal and preclinical

Submit your manuscript here: http://www.dovepress.com/open-access-journal-of-contraception-journ studies relating to understanding the biological mechanisms and practical development of new contraceptive agents. The manuscript management system is completely online and includes a very quick and fair peer-review system. Visit http://www.dovepress.com/testimonials. php to read real quotes from published authors. 